\title{
Nicolás Iñigo Carrera: Acervos familiares, experiencias universitarias, exploraciones teóricas: la formación de un historiador en Argentina, del primer peronismo a la dictadura
}

\author{
Carlos M. Herrera y Hernán Camarero \\ Centre de philosophie juridique et politique \\ Université de Cergy-Pontoise, Francia \\ Carlos.Herrera@u-cergy.fr
}

Desde los años 1990, Nicolás Iñigo Carrera se convirtió en uno de los historiadores marxistas que marcó las discusiones y los estudios sobre la clase obrera argentina, en particular a partir de su concepto de "estrategia". El fruto de este trabajo se materializó en la década siguiente, en particular en su libro La estrategia de la clase obrera. 1936 (2000). Estos últimos años, el programa se completó con otras obras, como La otra estrategia. La voluntad revolucionaria (2016), o más recientemente Las estrategias de la clase obrera en los origenes de peronismo (2019), investigaciones donde destacan la preocupación metodológica y la minuciosidad empírica, más allá de los debates que han podido generar, incluso en las páginas de esta revista. Nicolás ha jugado también un rol importante como animador del Programa de Investigación sobre el Movimiento de la Sociedad Argentina (PIMSA).

Si estas facetas son conocidas, quisimos abordar en esta entrevista el camino previo, lo que podriamos llamar sus años formativos, a partir de tres ejes: la vida familiar, marcada por la impronta socialista al ser nieto de Juan B. Justo y vivir con Nicolás Repetto, el tiempo de 
la formación historiográfica en los años 1960, en plena renovación de la Facultad de Filosofia y Letras de la UBA, y finalmente, las primeras experiencias en el campo de la investigación durante las dos décadas siguientes, llevadas a cabo en torno del Centro de Investigaciones en Ciencias Sociales (CICSO). Un arco de vida que cubre tres décadas de la historia argentina, del peronismo a la dictadura militar, en un marco de radicalización política.

Una versión más extensa de esta entrevista se halla en nuestro sitio web: www.cehti.org/

Quisiéramos iniciar el recorrido por el ámbito familiar ¿Cómo era la educación en tu hogar? ¿Se distinguia de la de tus amigos del mismo sector social?

La educación en el plano ético era muy estricta, basada en que "vos sabés lo que tenés que hacer", sin ningún tipo de castigos y acompañada de mucho cariño.

Mi padre nunca fumó ni bebió una gota de alcohol, tenía un absoluto rechazo por las aventuras galantes y los mujeriegos y por el juego, fuera lotería, carreras de caballos o naipes. Se levantaba a la 5 o 6 de la mañana para ir a la fábrica donde trabajaba (primero como empleado y después como socio) en Villa Lugano; iba en su auto Morris 8, pero alrededor de 1955 lo vendió y viajaba de Vicente López a Villa Lugano en colectivos. Volvía alrededor de las 6 o 7 de la tarde, excepto los sábados en que lo hacía al mediodía. Había sido muy deportista, era muy lector. Era muy jovial y con mucho humor, muy burlón, bien porteño.

La educación que recibimos fue bastante diferente de la de mis compañeros de colegio primario y secundario. En primer lugar, el ateísmo militante (no agnosticismo, considerado una burda negociación con la religión) y el anticlericalismo reforzado por relatos familiares sobre cómo mi abuelo Segundo Iñigo Carrera, moribundo en el Hospital Santa María (Córdoba), había tenido que batallar contra los curas que querian que aceptara los ritos católicos. Mi abuelo murió teniendo junto a la cama un ejemplar de El capital -traducido por mi otro abuelo- y el padrón electoral del Valle de Punilla: una sintesis de la política del Partido Socialista (PS). Esto en una época en que todo el mundo se declaraba católico salvo unos pocos judíos o protestantes. En la primaria yo era uno de los dos o tres que iba a las clases de "Moral", alternativa a las clases de "Religión" a las que iba el resto.

También al tope de los valores estaba un muy fuerte rechazo al machismo. Esto también chocaba con la ideologia de algunos de mis compañeros de colegio que consideraban a las mujeres en un escalón inferior a los hombres, sobre todo intelectualmente. El rechazo era 
mayor aún a considerarla un objeto sexual. Lo que se postulaba era una absoluta igualdad entre hombres y mujeres, tanto en capacidades como en conductas. Sin embargo, en la práctica, podía subsistir cierta idea de protección a la mujer.

Otros elementos importantes eran el rechazo a la violencia, la ausencia de castigos, la prohibición de armas de juguete y el convencimiento de que se podía llegar al socialismo, difusamente presente como una sociedad más racional, sin diferencias sociales, por la vía del parlamento y la educación.

\section{¿Cómo recordás la relación de tus padres con el PS?}

Mi padre fue activo militante desde la niñez (mi abuela recordaba una conferencia callejera de mi padre de alrededor de 15 años, bajito y flaco, en que uno de los asistentes le dijo "Parla bene, ma non se le vede") 1o mismo que sus hermanos mayores. Fue secretario del centro socialista de la $17^{\text {a }}$ varios años; a comienzos de los años 30 formó parte de la mesa directiva del Comité Central de las Juventudes Socialistas, después fue miembro de la Junta Ejecutiva y secretario de varios congresos de la Federación de la Capital (1937-1943) así como de la comisión organizadora de las Fiestas de Confraternidad Proletaria. Mi madre, afiliada del centro de la $7^{\mathrm{a}}$, también militó, sobre todo en campañas electorales y en Nueva Argentina. Viviendo con Repetto y Fenia Chertkoff desde que tenía un año y medio, tuvo la política en su casa. Mi padre dejó de militar activamente aproximadamente en 1947, pero siempre siguió involucrado en el partido. ${ }^{1}$

\section{¿Cómo se integraba Nicolás Repetto en la vida familiar?}

Repetto estaba totalmente integrado a la vida familiar, pero tenía su actividad propia. Pasaba el día en su escritorio, leyendo (recibía publicaciones de todo el mundo), escribiendo o en reuniones. Hasta los 90 años iba a las reuniones del Comité Ejecutivo de las que volvía en trolebús a la una o dos de la mañana. Siempre compartimos los almuerzos y, en las sobremesas (larguísimas, aunque los chicos huíamos a jugar al

1. Nicolás Iñigo Carrera es hijo del matrimonio entre Sarita Justo (1910-1986), la sexta y última hija de la unión de Juan B. Justo y Mariana Chertkoff, y de Ismael (1911-1984), hijo de Victoria Tomasa Marnoni y Segundo Iñigo Carrera, quien tenía también una aquilatada militancia socialista, en la que se destacará otro de sus hijos, Héctor. Tras la muerte de su madre en 1912, Sarita fue criada por su tía Fenia Chertkoff y Nicolás Repetto, con quienes vivió hasta sus muertes, en 1928 y 1965; sus hermanas Leticia y Aurora Justo se casaron con Germán y Emilio Dickmann, respectivamente. 
futbol), el tema excluyente era la política y, derivada de ella, la historia. Jamás hablaban de futbol, carreras, mujeres o negocios. Salvo que Repetto tuviera reuniones fuera de casa también compartíamos las cenas, con mi padre incluido.

No tengo recuerdo de haber discutido con él en la adolescencia y poco en la época de la facultad. Me acuerdo de una discusión sobre José Luis Romero y la importancia que le daba a la historia medieval, que Repetto veía como parte de una ofensiva clerical.

\section{¿Y qué lugar ocupaba la figura de Juan B. Justo en la casa?}

Juan B. Justo era un modelo inalcanzable. Eran citados sus dichos, como "Si en la mesa de la vida algunos no tienen lugar es porque otros ocupan demasiado lugar", "El juego es el impuesto a los tontos", "A igualdad de capacidad, quien menos impone su persona más impone sus ideas", y estaba presente su definición de socialismo: "El socialismo es la lucha, en defensa y por la elevación del pueblo trabajador que, guiado por la ciencia, tiende a realizar una libre e inteligente sociedad humana, basada en la propiedad colectiva de los medios de producción". Por la vía parlamentaria y la educación. Pero también era el abuelo del que contaban anécdotas jocosas; tenía fama de burlón y cascarrabias. Repetto le tenía un respeto idolátrico. Se resaltaba su ética y su capacidad intelectual.

¿Cuál era la relación con Alicia Moreau entre los años 1950 y 1970?

Mis padres apreciaban mucho a Alicia. Y la veiamos con cierta frecuencia. La división del partido la alejó de Repetto, pero no de mis padres. Cuando me casé fue al Registro Civil y su regalo fue el libro Resurrección de Tolstoi; todo un mensaje. Con ella alguna vez discutimos sobre el peronismo. También recuerdo su irónico juicio sobre el psicoanálisis, que asimilaba a la confesión de los católicos.

En 1982 o 1983 me convocó a su departamento. Me dijo "Quiero hablar con los de 40 años, con los de 60 no me entiendo. Dicen que soy una soñadora. Me moriré soñando". Tuvimos una conversación sobre el futuro de Argentina, pero no nos pusimos de acuerdo.

\section{¿Cómo se vivió el peronismo?}

Mis padres fueron antiperonistas, pero nunca antiobreros. Jamás tuvieron cabida expresiones como "negros" o similares. Fuimos educados en el rechazo a toda forma de racismo y a la creencia en razas superiores o pueblos elegidos. El peronismo fue vivido como un desastre para el 
país, un engaño a los trabajadores y un robo de las banderas del PS. Lo cierto es que determinó nuestras vidas en muchos sentidos.

Cada tanto Repetto era vigilado: un "pesquisa" parado en la esquina durante todo el día en un barrio bastante descampado no pasaba desapercibido. Él estuvo exilado en Montevideo desde el 26 de julio de 1944 al 3 de septiembre de 1945; y habiendo nacido yo en mayo del 45, a mediados de julio fui llevado a que me conociera. Repetto fue apresado en dos oportunidades: en 1951, después del golpe de Menéndez, y en abril de 1953, después de las bombas en Plaza de Mayo y el incendio de la Casa del Pueblo. Hubo otros allanamientos en que no lo encontraron, porque había huido a tiempo. Recuerdo los policias de civil en la sala, su negativa a dejarle llevar el bastón y Repetto diciendo que su bastón no tenía espada ni cachiporra. Tengo un vivido recuerdo de las visitas a la comisaría $1^{a}$, cuando Repetto estuvo detenido junto con Carlos Sánchez Viamonte, y a la Penitenciaria Nacional de la calle Las Heras.

No hubo en nuestra casa una política de ocultamiento de la posición política. Mi madre, profesora de inglés en la Escuela Normal $n^{\circ} 1$ fue dejada cesante dos veces. La primera el 20 de agosto de 1945, por el decreto 18.921/45 firmado por el vicepresidente Perón y Antonio Benítez, que exoneraba a un grupo de profesores por convocar a una huelga en solidaridad con los profesores universitarios. Fueron reincorporados en octubre de ese mismo año. La segunda cesantía fue específica para ella, mediante el decreto 9.893 del 29 de octubre de 1952, firmado por el director General de Personal, por su negativa a dar clase sobre La Razón de mi Vida, asentada en una nota elevada a la Directora de la Escuela Normal $n^{\circ} 1$.

Esa misma actitud se esperaba de nosotros. En cuarto grado tuve como tarea preparar tres lecturas, alusivas a Perón, Evita y Stella Maris, la patrona de los navegantes; mis padres me dijeron "cuando tengas que dar la lección decís: yo para hoy no estudié porque en la escuela no hay que enseñar ni política ni religión"; orden que cumplí.

Después de la quema de la Casa del Pueblo circulaba el rumor de que serian incendiadas las casas de los dirigentes opositores (algo que nunca ocurrió). Mi madre se negó a dejar la casa. Pero sí cuando los golpes de junio y septiembre de 1955. Mis padres fueron a la casa de mi tío Miguel y nosotros a la casa de mi tía Leticia y Germán Dickmann. En septiembre nos quedamos hasta que se definió la situación. Y fuimos a la Plaza de Mayo donde una multitud vivaba la libertad y gritaba "Si este no es el pueblo, el pueblo dónde está". (Me llevaría unos diez años empezar a darme cuenta de que la mayoría del pueblo no estaba justamente en esa plaza.) Fue el primer acto político multitudinario en que estuve. Tenía 10 años.

Otro recuerdo imborrable fue la ruptura de relaciones con Enrique y 
Emilio Dickmann, este último casado con mi tía Aurora. Nuestra casa era lindera con la casa de Enrique por los fondos, separados los terrenos por un cerco vivo, y con la de Emilio por el costado, sin cerco entre ellas, sólo con una pirca de unos $50 \mathrm{~cm}$ de alto. Nuestro compañero de juegos era nuestro primo Emilio (h), dos años mayor que yo. En 1952 Enrique y Emilio se entrevistaron con Perón y fueron expulsados del PS y de la familia. A nosotros nos indicaron "Con su primo no juegan más" y se levantó un cerco de alambre entre las dos casas. Y, efectivamente, no nos tratamos con mi primo por varios años. Lentamente se fue levantando la excomunión y, después de varios años, Emilio y Aurora estuvieron en alguna de las navidades multitudinarias que organizaba mi madre. Pero mi tía Leticia Justo nunca más les dirigió la palabra.

\section{¿Dónde cursaste la escuela primaria y luego el secundario?}

El peronismo influyó en la decisión de mandarnos a hacer la escuela primaria en colegios privados, donde, presuntamente, no estariamos tan expuestos a molestias por la posición política de la familia. Empecé la primaria en 1951, en el colegio William Hudson, donde había hecho el Jardín de Infantes. Tenía pocos alumnos y sólo los dos primeros grados. Después pasé al Westminster College, un típico colegio inglés donde nos daban la preparación para ser funcionarios coloniales, con libros traídos de Inglaterra. Mi ruptura con esa cultura inglesa comenzó, vagamente, cuando Inglaterra, Francia e Israel atacaron Egipto en 1956.

En 1958 entré al Colegio Nacional de Vicente López, creado unos seis años antes. Primer año lo cursé en el edifico del "anexo" del colegio que un año después tuvo que ser abandonado porque se derrumbó el techo. La sede central era un edificio del siglo XIX y unas casillas prefabricadas. Todo se basaba en el esfuerzo de (algunos) profesores.

Ese año 1958 fue el de la elección de Frondizi y de la huelga y movilizaciones por la enseñanza laica. Antes de las elecciones hubo una gran movilización en favor de la fórmula presidencial del PS Palacios-Sánchez Viamonte, que en las pintadas, aprovechando la P y la S enlazaba los nombres de los candidatos con la sigla partidaria, y recuerdo el escándalo de mis padres porque los jóvenes socialistas, en lugar de marchar cantando las consignas de rigor, bailaban al grito de "Vote, vote, vote al hombre del bigote".

El conflicto laica-libre llegó un día al Anexo del colegio, donde éramos alumnos de primer año. Alguien planteó que no había que entrar a clase, pero nadie decía por qué. Y yo entré. Cuando volví a casa mis padres se horrorizaron: "iQué nadie se entere!". Por supuesto que desde ese día cumplí con la huelga. Un día marchamos desde el Anexo hasta la sede del colegio (unas 20 cuadras); a los alumnos de los años superiores 
les llegó el rumor de que un grupo de estudiantes venía a obligarlos a plegarse a la huelga y estaban preocupados hasta que vieron llegar al grupo de niños de 13 años. Un solo policía nos corrió.

En el colegio fui más o menos buen alumno. Era uno de los que "hablaba de política". Fui delegado al Club Colegial (creo que fue cuando cursaba tercer año), una especie de centro de estudiantes impulsado desde las autoridades educativas y en el que nos reuníamos unos pocos estudiantes, entre ellos mi hermano Juan, y que duró un suspiro.

\section{¿Cuáles fueron tus vivencias de la ruptura partidaria de 1958?}

Con la fractura se dividió la familia y también mi casa. Repetto y Andrés Justo fueron figuras del Partido Socialista Democrático (PSD), Germán Dickmann, mi tía Leticia y el resto de los hermanos de mi madre se alinearon con ellos. Alicia Moreau, mi tío Héctor Iñigo Carrera y mis padres quedaron en el Partido Socialista Argentino (PSA). Cuando se dividió el PSA mi padre fue afiliado del efimero Movimiento Socialista Principista que encabezaba mi tío Héctor.

En la división del 58 hubo fuertes discusiones entre Repetto y mi madre; mi padre no participaba de esas discusiones que ocurrian mientras él estaba en el trabajo. Sin embargo, creo que nunca estuvo en cuestión el afecto filial construido en los 45 años que mi madre llevaba viviendo con Repetto.

La que sí quedó muy afectada fue la relación entre Repetto y Alicia Moreau; la relación entre Héctor y Repetto se recompuso.

La ruptura del PS fue uno de los hechos que más incidió en mi vida. Se daba por sentado que al cumplir 14 años me afilaría a las Juventud Socialista (JS), pero con la división la orden que recibí de mis padres fue la de no afiliarme y eso marcó para siempre mi relación con los partidos. Se puede contribuir a la transformación de la sociedad sin estar dentro de un partido; lo que no significa que se pueda prescindir del partido.

¿Qué representaba para vos el PS cuando entraste a la universidad? ¿Y cómo era tu visión de las otras izquierdas, como el PC o incluso la huella del EGP en la Facultad?

Cuando entré a la universidad tenía simpatía por lo que iba quedando del PSA. Creía firmemente en la democracia representativa. Creo que voté por el PSA en 1965 (primera vez que votaba). El Partido Comunista (PC) era algo lejano. En mi casa había un fuerte sentimiento anti-PC, producto de diferencias ideológicas, pero también de los choques entre militantes de ambos partidos en la época de mayor militancia de mi padre que se indignaba recordando que los llamaban "socialfascistas"; la 
escisión del Partido Socialista Obrero (PSO) era vista (al menos en parte) como resultado de la infiltración comunista; mi madre recordaba con indignación los virajes del PC durante la guerra mundial. La simpatía por la revolución cubana no pasaba por aceptar al PC. En cuanto a los grupos y partidos trotskistas creo que ni sabia de su existencia. Entré a la facultad en 1963 y recuerdo el clima tenso en el patio de Viamonte 430 cuando surgió Vanguardia Revolucionaria (el grupo impulsado por Juan Carlos Portantiero). Pero me era ajeno. En la facultad había un clima de simpatía con el Ejército Guerrillero del Pueblo (EGP) y el Consejo Directivo hizo una declaración que fue muy criticada por la derecha a nivel nacional.

\section{¿Como veías a los principales agrupamientos estudiantiles en aquellos años?}

Se suele afirmar que las agrupaciones estudiantiles no eran el brazo de un partido político, aunque militantes de partidos formaran parte de ellas y las orientaran. Esa característica estaba dejando de ser cuando entré en la facultad. En ese momento se estaba produciendo las crisis del PS y el PC, sobre todo por las vías del cambio social y la relación con el peronismo y los trabajadores; aparecían (y desaparecían o se transformaban) múltiples organizaciones.

En 1964-1965 el reformismo, que históricamente reunía a socialistas, comunistas, radicales, había sufrido múltiples escisiones. Existian el Movimiento Universitario Reformista (MUR), conducido por los adherentes al PS de Izquierda Nacional: Ernesto Laclau, Ana Lía Payró y José Luis Fernández (que eran consejeros), y el MAR, ligado a una parte de Vanguardia Revolucionaria. El resto había surgido en 1963 y 1964: la Linea de Izquierda Mayoritaria (LIM), de Roberto "Pajarito" Grabois, (que venía del PS y poco después formaría el Frente Estudiantil Nacional y se incorporaría al peronismo) y Daniel Hopen (militante de Palabra Obrera y luego del PRT); la Tendencia Antiimperialista Universitaria (TAU), aliada a LIM en el Frente Antiimperialista, cuyos dirigentes eran Norberto Wilner y Juan Samaja; Acción Reformista de Filosofia y Letras (ARFYL) orientada por la Federación Juvenil Comunista que tenía como figuras a Isidoro Cheresky, Oscar Landi y Beatriz Schmukler; un diminuto Movimiento Humanista Renovador, donde algo después militaba Norberto Ivancich. Y AUDE, donde se agrupaba la derecha, que la iban de apolíticos y sólo gremiales, con poca presencia en el estudiantado movilizado pero que ganaba las elecciones en algunas carreras y que reunía desde los conservadores hasta el PSD. El peronismo no existía como tal (ANDE, la agrupación asumidamente peronista, era diminuta, no participaba de las elecciones ni de la política cotidiana en la facul- 
tad), lo que da la pauta de cuán encerrada en sí misma estaba la "isla democrática"; creo que fue en la segunda mitad de 1965, ya en la sede de la calle Independencia, que alguien pegó unos retratos de Perón y Evita y José Luis Romero, el decano, fue hasta el hall y los arrancó con sus propias manos.

Todas las agrupaciones excepto AUDE coincidian en rechazar el academicismo y el cientificismo y reivindicaban la cultura nacional, la lucha por la liberación nacional y eran fuertes críticos del gobierno radical de Arturo Illia, instalado sobre la proscripción del peronismo, y de su política presupuestaria en la universidad. En las manifestaciones por el aumento del presupuesto universitario marchábamos al grito de "Illia, Perette/gorilas y amarretes". La movilización más importante fue contra la invasión de las tropas de Estados Unidos a Santo Domingo (1965) y la guerra de Vietnam estuvo siempre presente, dando lugar a declaraciones "de repudio" y "de preocupación" respectivamente por parte del Consejo Directivo. Entre los estudiantes se vivía un clima de radicalización general, al mismo tiempo que una relectura del peronismo, que se acentuó después de 1966.

¿La militancia política fue una opción para vos en esos años $60 ?$ ¿En qué consistió tu activismo estudiantil?

A mi militancia en la carrera de Historia (1964-1965) la definiría como gremial. En aquel tiempo las carreras eran gobernadas por un director, la junta departamental y la asamblea departamental, de la que formaban parte todos los profesores y 4 representantes de los estudiantes, que era bastante decorativa y, de hecho, sólo se reunió una vez mientras fui delegado.

A diferencia de Sociología, Psicología y Antropología, carreras en la que el MUR (y después MUR-MAR) ganó todas las elecciones del claustro estudiantil desde 1959 en adelante, en Historia AUDE ganó la mayoría en 1959, 1961, 1962 y 1963. En 1964 ganó la lista del MUR-MAR, con José Luis Fernández, delegado titular a Junta y Ana Lía Payró como suplente, apoyados por un grupo muy movilizado de estudiantes, del que formé parte, que impulsó y logró el levantamiento de las correlatividades, concursos, la aprobación por la Junta Departamental de la Licenciatura en Historia Social y el reemplazo de los niveles 4 y 5 de Latín o Griego por materias optativas y seminarios.

Al fin del año las tensiones que venian produciéndose estallaron cuando Fernández y Payró se negaron a apoyar la designación de Tulio Halperin Donghi en Historia Argentina I, contra la voluntad de la mayoría de los estudiantes que participábamos en "la delegación". Paralelamente, algunos de los compañeros se habían incorporado al 
Frente Antiimperialista (LIM-TAU). En consecuencia, formamos nuestra propia lista para las siguientes elecciones. Después de discutir el nombre (tengo muy presente la oposición de los compañeros del TAU a que la palabra "Reformista" formara parte de nuestro nombre; claro, jeran revolucionarios!) nos presentamos como Lista Unificada de Historia con un programa que planteaba: numerosas materias optativas, seminarios de especialización, seminarios libres, cátedras paralelas, supresión de los latines y griegos, creación de las Licenciaturas en Historia Argentina y Americana y en Historia Social y Económica; y para Historia del Arte (que estaba dentro del Departamento de Historia): creación de una especialización en Música, formación de críticos e investigadores, supresión de correlativas, concursos para ayudantes rentados alumnos. Ganamos las elecciones con 143 votos contra 89 votos de AUDE y 53 del MUR. El padrón de estudiantes de historia era de alrededor de 400 alumnos, la mitad de Historia del Arte, de los que votaron 314.

Fuimos elegidos: Juan Carlos Grosso (TAU) como delegado titular a Junta y Alberto Collazo (ARFYL) como suplente. Y como delegados titulares a asamblea Alberto Collazo (ARFYL), Luis Alberto Romero (TAU), Nicolás Iñigo Carrera (Independiente) y Susana Bianchi (Independiente) y como suplentes Diana Epstein (Independiente), Lilia Ana Bertoni (TAU), Graciela Dragosky (Independiente) y Marta Calviño (TAU). Collazo y Dragosky eran alumnos de Historia del Arte. Desde la delegación teniamos un fluido contacto con los consejeros estudiantiles; en mi caso, sobre todo con Daniel Hopen (Frente Antiimperialista LIM-TAU), José Luis Fernández (MUR) y Alicia Sirkin (ARFYL).

\section{¿Concretamente, qué tipo de tareas llevaban a cabo?}

Nos propusimos hacer un informe por materia. Los temas dan una buena idea del clima de la carrera en este aspecto: extensión del programa, si lo que se enseña es historia "contada", historia politica o "algo más", extensión de la bibliografia, si es obligatoria, moderna, interesante; si el examen se da sólo con las clases o hay que leer; cómo son los prácticos, si hay discusiones; si hay que repetir la lección, como en el colegio secundario o hay trabajo creativo del alumno. En sintesis, la confrontación era con la "historia tradicional" y la enseñanza "tipo secundario" presentes en la carrera más que la referencia a grandes debates historiográficos.

Pero donde se dio la pelea más fuerte fue para que se creara una cátedra paralela de Historia de América II (América independiente). Su titular era Julio César González, que lo mismo que Luis Arocena (titular de Introducción a la Historia e Historia Moderna y director del departamento), Luis Aznar (vicedecano y titular de América I colonial) 
y el mismo José Luis Romero eran antiguos afiliados al PS. La historia que enseñaba González se limitaba al siglo XIX, centrada en lo político; nosotros queriamos una orientación que diera más importancia a lo económico-social y a los procesos contemporáneos, y proponíamos la cátedra paralela a cargo de Alberto Plá. Esta propuesta rompía el acuerdo de hecho que existía acerca de los espacios que ocupaban los profesores de orientación "tradicional" (historia fáctica político-institucional) y los "renovadores", agrupados en el Centro de Estudios de Historia Social, dirigido por Romero. Es por eso que las resistencias no venían sólo de los consejeros graduados de la derecha sino también de una parte de los profesores que se declaraban herederos de la Reforma Universitaria. En la sesión del Consejo Directivo en que debía votarse, la propuesta tenía mayoría; Romero se retiró porque se nombró el papel de Luis Alberto en la delegación estudiantil; Aznar, que pasó a presidirla, se retiró también, dejándola sin quórum, ganando así tiempo para reunir votos adversos. La siguiente sesión fue precedida por un episodio oscuro: alguno de los compañeros sugirió hacer un cartel que consistía en un largo rectángulo vertical al lado de un cuadrado bajito con la leyenda "En su lucha contra la cátedra paralela Don Quijote encontró su Sancho Panza", obvia alusión a Arocena, que era flaco y alto, y a Aznar, bajo y gordo. A pesar de que el cartel era bastante bobo se generó un escándalo, al que abonó Aznar diciendo que había sido amenazado por una llamada anónima. La sesión del CD giró sobre "la ofensa" inferida al vicedecano. Halperín Donghi, afirmó que como reformista no podía sino votar a favor, pero dio todos los argumentos para votar en contra; Telma Recca, con cuyo voto contábamos, votó en contra lo mismo que Aznar, los tres consejeros graduados por la mayoria, y otros profesores que no recuerdo. Finalmente, perdimos. Aznar presentó su renuncia, y la Delegación Estudiantil presentó una nota declarando que no había tenido intención de agraviar a Aznar y se unió a los pedidos para que la retirara. Una derrota, aunque los compañeros del TAU la vivieron como un triunfo por haber logrado presentar una opción "auténticamente renovadora".

Para entonces la facultad ya se había mudado a la calle Independencia. El hall central estaba en permanente ebullición, con actos, asambleas y discusiones. El movimiento estudiantil de Filosofia y Letras era el más radicalizado junto con el de Ciencias Exactas. Pero a diferencia de Exactas esa radicalización era percibida como del conjunto de la facultad: en 1965 la Federación Argentina de Entidades Anticomunistas (FAEDA) publicó una serie de solicitadas denunciando "la infiltración comunista" en el país y en la correspondiente a la universidad incluyó a la casi totalidad del Consejo Directivo de la facultad, incluyendo a Romero y Aznar y nombres tan improbables como Ana María Barrenechea 
y Tulio Halperín Donghi. Las denuncias contra la facultad de Filosofia y Letras llegaron al Congreso Nacional: en la sesión de 20 de agosto de 1965 la Cámara de Diputados debatió el tema y la Facultad de Filosofia y Letras fue analizada como ejemplo de "infiltración comunista" entre los estudiantes y profesores. En 1965 o primeros meses de 1966 un grupo "nacionalista" (creo que la Guardia Restauradora Nacionalista) entró disparando algún tiro a la sede de Independencia 3065 para tomar un local estudiantil; hubo corridas y los estudiantes logramos atrapar a uno que fue entregado a Aznar y por éste a la policía.

En ese clima José Luis Romero renunció al decanato, lo que dio lugar a una multitudinaria peregrinación a su casa en Adrogué, con discursos de los dirigentes de las distintas agrupaciones. También juntamos firmas pidiendo que la retirara; en mi caso, todos los estudiantes y profesores a los que le pedí firmaron, con una excepción: Perla Fuscaldo, que me dijo que Romero había cosechado lo que sembró. Romero retiró la renuncia, pero volvió a presentarla enseguida.

¿Qué cambio con el derrocamiento de Illia y el inicio de la "Revolución Argentina"?

En 1966 se cerró la primera etapa de mi carrera, con diez materias aprobadas y un par más cursadas. Ese año fui a hacer el servicio militar y no cursé ninguna materia. No participé de la ocupación del edificio de Independencia ni del consiguiente desalojo, que no tuvo la espectacularidad de la Noche de los Bastones Largos.

Cuando volví a cursar y rendir en 1967 era otra facultad, controlada por la policía, con exhibición de libreta universitaria para entrar. No tanto en lo que hacía a los profesores: a diferencia de Sociologia, donde entre renunciantes y exonerados prácticamente había desaparecido el cuerpo docente, en Historia los renunciantes fueron pocos. La radicalización iba en buena medida de la mano de una nueva presencia del peronismo, con las Cátedras Nacionales. Cursé dos materias en esas cátedras: "Sindicalismo Argentino", en 1969, dictada por Gonzalo Cárdenas, y "Sociología de la Cultura Latinoamericana", en 1971; la primera tenía que ver temáticamente con mis intereses, la segunda simplemente para completar el número de materias necesarias para recibirme.

Aunque seguía en contacto con el grupo que habíamos formado parte de la delegación, ellos se fueron recibiendo, y yo me vinculé a Alberto Calou, Enrique Tandeter y Juan Carlos Garavaglia, que habían entrado más tarde a la facultad. También tenía relación con Norberto Ivancich (MHR), que me pasaba los materiales de la CGTA y de la huelga de petroleros.

Entre 1967 a 1970, mi relación de compañeros de curso era más bien 
con estudiantes de agrupaciones peronistas (el Frente Antiimperialista y la Línea Antiimperialista Nacional formaron el Frente Estudiantil Nacional; el MHR, FA y estudiantes antiimperialistas formaron el Frente de Agrupaciones Nacionales), algunos de ellos muy ligados a la CGT de los Argentinos. Recuerdo también algunos del Frente de Agrupaciones Universitarias de Izquierda (FAUDI) del Partido Comunista Revolucionario (PCR) y de la Tendencia Estudiantil Revolucionaria Socialista (TERS) de Política Obrera. Fuera de la facultad mi relación era con Calou, Garavaglia y Tandeter (recuerdo haber ido algunas veces a jugar al fútbol en quintas que alquilaba Enrique junto con Portantiero y otros) y el CICSO. Ya no existía la representación estudiantil, pero creo recordar que a punto de recibirme en 1971 formé parte de una delegación de estudiantes que nos entrevistamos con el decano Ángel Castelán.

La actividad política seguía presente en la facultad. Las asambleas, ilegales, se hacían en la iglesia metodista de la calle Camacuá y en una sede del sindicato telefónico (FOETRA); supuestamente eran "clandestinas". En ellas se daban fuertes enfrentamientos entre las corrientes políticas. La asamblea en FOETRA se hizo en un patio cubierto con un toldo corredizo; el calor obligaba a plegar el toldo, pero cuando las discusiones subian de tono y se llegaba a las manos se volvía a correr para que no vieran los vecinos. En esa asamblea un militante del POR-T tomó provocadoramente la palabra para "denunciar el asesinato del Che en las cárceles estalinistas de Cuba"; no alcanzó a terminar la provocación cuando fue levantado y pasado por encima de las cabezas de los asambleístas y arrojado a la calle.

En alguno de esos años, después de una corrida en la puerta de la facultad, fui preso por un día en la comisaría $8^{a}$. La participación en manifestaciones y actos políticos ya pasaba por fuera de la facultad, aunque las convocatorias solían venir por ese lado. En el primer cuatrimestre de 1968, con Garavaglia cursamos Geografia Humana, que dictaba Elena Chiozza; en junio fuimos con él y otras dos personas a la movilización a Plaza Miserere en la huelga declarada por la CGTA en repudio al segundo aniversario del golpe de estado de 1966 . Un cerrojo policial imposibilitaba el acceso a la plaza; mientras caminábamos buscando llegar, Garavaglia y su amigo fueron apresados por una pareja de policías de civil e inauguraron la cárcel de Ezeiza. Chiozza, a pesar de su antiperonismo, tuvo una actitud loable: enterada de la situación, esperó que saliera de la cárcel para tomarle examen.

Cuando se dio la apertura previa a las elecciones del 73 casi todos mis antiguos compañeros y amigos volvieron como docentes a la facultad. Yo, siguiendo la política marcada por el CICSO, sobre todo para la UBA, no volví. 
¿Cuáles eran los debates fundamentales: la cuestión del cientificismo, el peronismo, el impacto de la revolución cubana $y / u$ otros?

En la facultad anterior a 1966 había dos enemigos: el academicismo (los profesores de la vieja escuela, por ejemplo, Caillet-Bois) y el cientificismo, que era la búsqueda de la rigurosidad científica al margen de las condiciones y necesidades reales del país. Si uno repasa los programas de todas las agrupaciones (con excepción de AUDE) va a encontrar la referencia al cientificismo como corriente a combatir. Sin embargo, no recuerdo que en Historia se fuera más allá de lo declarativo: no recuerdo mucha denuncia del subsidio que el Centro de Historia Social recibió de la Fundación Marc Bloch como sí lo hubo en Sociología por el subsidio de la Fundación Ford. Probablemente porque nuestra mayor confrontación era contra la historia tradicional.

La discusión acerca de los subsidios de fundaciones extranjeras se prolongó con el Proyecto Marginalidad. Asistí a las virulentas asambleas en la Sociedad Argentina de Artistas Plásticos, en la calle Florida, en las que Carlos Bastianes, Daniel Hopen, Santos Colabella e Ismael Viñas denunciaban ese Proyecto, frente a Pepe Nun, Murmis, Balvé y Néstor D’Alessio. Pese a sus afirmaciones en contrario, la posición de los primeros, sintetizada en un documento del Frente Antiimperialista de Trabajadores de la Cultura (FATRAC), probablemente escrito por Bastianes y Hopen, llevaba a la imposibilidad de realizar investigación científica: no sólo la impugnaban por recibir subsidios de fundaciones estadounidenses, sin importar los recaudos que se tomaran en cuanto al uso de la información recogida, sino porque el imperialismo estaba en mejores condiciones para aprovechar los resultados de cualquier investigación.

En cuanto al peronismo más que tema de debate había una coincidencia (sin duda con matices que iban desde el rechazo a su proscripción hasta la incorporación al peronismo) en rever el antiperonismo que había sido rasgo saliente del movimiento estudiantil. La revolución cubana era asumida por todas las agrupaciones, excepto por algunos trotskistas. No recuerdo debates sobre ella. Había bastante coincidencia, al menos discursiva, en que una transformación radical de la sociedad sólo era posible por la vía armada.

\section{¿Cuáles son tus recuerdos de José Luis Romero?}

Conocí a Romero como alumno y mi bastante breve relación con él fue como parte del grupo que nos referenciábamos en la cátedra de Historia Social. En 1964 cursé y aprobé Historia Social General, que dictaban Romero como titular, Tulio Halperin Donghi como adjunto, 
Reyna Pastor y Alberto Plá como Jefes de Trabajos Prácticos y Margarita Pontieri y Leandro Gutiérrez como ayudantes. La facultad funcionaba en Viamonte 430 y en otros lugares, entre otros el Centro de Estudios de Historia Social en la calle Lavalle, donde, junto a los integrantes de la cátedra de Historia Social, anidaban los que diez años después formarian parte de las comitivas de Martinez de Hoz.

Con Historia Social se me abrió un panorama, no sin cierta resistencia inicial, de lo que era el análisis histórico en términos de clases sociales y lucha de clases; significó una ruptura. Romero tenía una perspectiva teórica próxima al marxismo (sin serlo). Sus clases eran realmente magistrales, uno salía deslumbrado por la exposición. También fue una novedad el trabajo con fuentes que hacíamos en los trabajos prácticos, lo mismo que en Historia Medieval e Historia Antigua I (Oriente). Después de su renuncia, Romero organizó en su casa un seminario sobre el mundo urbano del que participé poco. Mi interés iba ya por la historia de la clase obrera argentina y el tema del seminario no me convocaba.

¿Qué materias te atrajeron de la carrera? En esos años la Escuela de los Annales era una referencia ineludible, pero también habia cierta influencia marxista. ¿Cuánto te marcaron estas concepciones historiográficas?

Mi interés desde antes de entrar a la facultad era la historia argentina. No puedo precisar si ya entonces me interesó la historia de la clase obrera. Es curioso que recién a fines de los años 80 pudiera investigar en esa área. Las materias que me resultaron más atractivas fueron Historia Social, por su enfoque, y Medieval y Antiguo Oriente, sobre todo por el análisis de fuentes. Y las "Argentinas". Historia Argentina I la cursé con Halperin Donghi; Argentina II con Ricardo Caillet-Bois en 1968.

En la carrera de Historia la presencia de Marx era muy escasa. Se asumían marxistas Plá, Reyna Pastor, Leandro Gutiérrez. No sé Romero. Halperín Donghi no; su materia tenía como bibliografia la Historia de la Academia, Celesia, Bosch Garzón, Irazusta, Zinny, ningún marxista. En Historia Social lo único que leíamos de Marx eran fragmentos de La lucha de clases en Francia, y no como bibliografia sino como fuente, lo mismo que La situación de la clase obrera en Inglaterra de Engels; la bibliografia incluía unos pocos marxistas, pero no era de esa orientación en su mayoría. El seminario de Plá incluía en la bibliografia a Sweezy, Baran, Kondratieff, Godelier, pero no a Marx.

La concepción de la historia como un proceso social en el que el conflicto tenía un lugar central me enriqueció y me permitió superar la mirada limitada a la historia política sin caer en el compartimento estanco de la historia económica. 
Luego fueron años de intensos debates sobre el marxismo ¿Qué Marx empezaste leyendo? ¿qué modelo de historiador marxista era el que más te habia marcado? ¿Cuánto circulaban o eran discutidas las posiciones de Bagú, Puiggrós o Peña? ¿Los debates Dobb-Sweezy, la obra de los franceses Vilar y Soboul, o de Rudé, Hill, Hilton, Hobsbawm y Thompson?

En la primera mitad de los 60 mi lectura de Marx no iba más allá del Manifiesto, que creo había leído en mi casa, y los textos que veíamos como "fuentes de la época" en Historia Social. El Marx que conocía era el de Juan B. Justo, y poco. Mi aproximación a los clásicos del marxismo fue la lectura de las obras más "históricas" de Trotsky: la Historia de la Revolución Rusa y su autobiografia; también La revolución permanente editada en dos pequeños tomitos por Coyoacán. También los Relatos de la guerra revolucionaria del Che y otros libros sobre la revolución cubana.

Mi lectura sistemática de Marx comenzó en el CICSO, con el curso de lectura del primer tomo de El capital que hice en 1970 y 1971 con Pancho Aricó, que estaba en la onda althusseriana de empezar por el capítulo 4. Un poco después leí la sección séptima del tomo III, en el marco del trabajo con Murmis, lo mismo que La cuestión agraria (Kautsky) y El desarrollo del capitalismo en Rusia y otros textos de Lenin sobre las distintas vías de expansión del capitalismo en el campo. En 1975 hice otro seminario en CICSO sobre el primer tomo de El capital, con Elio Londero. Los libros II y III los leí bastante después de manera irregular; la lectura sistemática la hicimos en PIMSA en los años 90.

Con el repliegue del 76, fue cuando leí más: empezando por los textos que habian sido el eje de un seminario que dirigió Marín en 1974 sobre las leyes de la lucha de clases, cuya grabación tenía Balvé: La guerra de campesinos en Alemania, El 18 Brumario, La lucha de clases en Francia. $\mathrm{El}$ texto que más me impactó fue El trabajo alienado (Manuscritos económico-filosóficos) que leímos en una traducción que había publicado el PSA de Vanguardia; El trabajo alienado le da una perspectiva a Trabajo asalariado y capital o Salario, precio y ganancia y rompe cualquier lectura economicista de Marx. Más o menos en esa época leí La cuestión judia, Miseria de la Filosofia (en particular el punto sobre las coaliciones obreras) y La ideología alemana para la definición de clase. Las relaciones sociales en Rusia de Engels y Análisis de situación. Relaciones de fuerza de Gramsci muestran la relación entre estructura y superestructura, la relación entre necesidad y voluntad. De Gramsci también Maquiavelo, Los intelectuales y la organización de la cultura, inescindible de Lenin (¿Qué hacer?, El estado y la revolución).

Los debates Gunder Frank-Puiggrós y Dobb-Sweezy formaban parte del "Seminario de perfeccionamiento Modos de producción y sistemas económicos", a cargo de Ernesto Laclau, Reyna Pastor y María Elena 
Vela de Ríos, que fue el primer curso que hice en CICSO y en el que leí Formaciones económicas precapitalistas y especialmente sobre modo de producción asiático (Wittfogel, Godelier, Mandel). A Hobsbawm (Las revoluciones burguesas) y Soboul los leí en Historia Contemporánea. Rebeldes primitivos, que es el libro de Hobsbawm que más me interesó, en el grupo de trabajo sobre "Historia del movimiento obrero en Argentina", que coordinaban Gutiérrez, Moreno y Torre, en el CICSO en 1969. Quizás en ese mismo grupo vimos La multitud en la historia o lo leí por mi cuenta. A Thompson lo conocí en 1980, por recomendación de Marín.

\section{¿Cuánto dirías que influyó la cultura de los 60 en tu radicalidad?}

No creo que haya influido mucho, salvo en el pelo largo, la barba y la informalidad en el vestir.

\section{¿Cuándo comienza a cambiar tu visión del peronismo?}

La lectura de Belloni y Ramos y las charlas con los compañeros de la facultad ponía en crisis la idea del peronismo que tenía desde mi infancia. Si, como afirma el programa de la Asociación Internacional de Trabajadores, la emancipación de la clase obrera será obra de la clase obrera misma, y en Argentina esa clase es mayoritariamente peronista, será la experiencia de lucha de esa clase obrera real la que conduzca a su emancipación. No se trata de impugnar su ideología, al estilo de las sectas portadoras de la "verdadera" conciencia de clase, sino de marchar junto a ella en su proceso de luchas que, quizás, le permita construir una conciencia socialista.

¿Significa esto que hay que hacerse peronista? No. Y menos aún en la producción de conocimiento, que necesita de instrumentos teóricos que el peronismo no brinda. Casi siempre voté al peronismo y participé de las movilizaciones por el retorno de Perón en noviembre de 1972 y junio de 1973, así como del Devotazo. El peronismo en el gobierno me convocó mucho menos. No estaba en Buenos Aires en junio-julio de 1975, pero hubiera participado de esas jornadas.

En los años 70 ¿en qué consistían tus simpatías politicas?

Acompañé las movilizaciones por el retorno de Perón en 1972 y 1973. Participé también de la movilización el 20 de junio de 1973, pero ya las condiciones eran diferentes: el enfrentamiento entre la Tendencia y el movimiento sindical me parecía un desastre y no me sentía identificado con lo que estaba ocurriendo; me queda el recuerdo imborrable de la sensación de derrota que daban los grupos caminando de regreso, lle- 
vando a la rastra por el suelo sus banderas. Así como consideraba que había que acompañar al pueblo en su lucha por el retorno de Perón, no me sentía identificado con el peronismo en el gobierno sino con la continuidad de las luchas. Creo recordar que colaboré con algún artículo sobre historia de luchas obreras para la publicación del Movimiento Sindical de Bases. Estuve en el $5^{\circ}$ congreso del Frente Antiimperialista y por el Socialismo (FAS) en Presidencia Roque Sáenz Peña, donde tuve oportunidad de escuchar, entre otros, a Agustín Tosco.

¿De qué modos pensás que aquel periodo de intensa lucha de clases, radicalización ideológica y extrema politización abierto en 1969 marcó la dinámica de los ámbitos específicos en los que te movias?

Ninguno de los ámbitos en que me movía quedó al margen de ese proceso de radicalización. Y ningún ámbito en el país y en el mundo, en un sentido u otro. Los relatos sobre el periodo hacen referencia a la ausencia de "democracia representativa" como razón para esa radicalización: los sucesivos golpes de estado y la proscripción de la fuerza política mayoritaria, lo que daba un tinte fraudulento a las elecciones. Es el discurso que enfatiza la resistencia popular como una lucha por la democracia.

Pero la radicalización fue resultado de un proceso más profundo, orgánico. La ofensiva de la oligarquía financiera, por la necesidad de revertir la caída de la tasa de ganancia y de neutralizar los procesos de liberación que se venían desarrollando desde fines de los 40, planteaba cómo sería la sociedad. En Argentina el desarrollo capitalista había encontrado trabas que sólo podía superar con un generalizado proceso de expropiación por el capital, resultante del pasaje de un desarrollo capitalista en extensión a un desarrollo en profundidad, con el consiguiente proceso de concentración del capital y centralización de la riqueza. Esta situación creó las condiciones para que todas las clases y fracciones sociales, sea porque veían en peligro su posición en la sociedad o porque se propusieron ocupar otra posición, se lanzaron a una lucha por imponer al conjunto de la sociedad formas distintas de organización social. Cuando se define la forma de organización social y está en juego la misma existencia de fracciones sociales, la situación se dirime mediante el uso de la fuerza armada.

El triunfo de la fuerza acaudillada por la oligarquía financiera, con base en buena parte de la pequeña burguesía, estableció la Argentina que tenemos hoy, en la que la mayoría de la población es sobrante para el capital, una democracia en la que un presidente pudo decir "Si decía lo que iba a hacer, no me votaban", y en la que una parte creciente de la población no come, ni se cura ni se educa. Sin restarle importancia 
al elemento voluntad, considero que no puede despreciarse el proceso orgánico que creó las condiciones para la intensidad y generalidad que tomó el enfrentamiento social.

Tuviste una relación fuerte con la sociología ¿Fue anterior a la experiencia del CICSO?

Mi relación con la sociología se dio a partir del trabajo con Murmis sobre las clases sociales, en particular en el campo, y los procesos de proletarización y campesinización y el uso de datos censales para analizar estructura de clases. No cursé Introducción a la Sociología (cursé Antropologia) ni Sociología Sistemática. Leí poco a los funcionalistas, cuando trabajé el tema rural y con Esther Hermitte, y un poco más a los franceses de sociología del trabajo. Lo que sí me influyó mucho es la centralidad dada a la investigación empírica. La necesidad de demostrar con datos lo que se está afirmando y, de ser posible, cuantificarlo.

¿Cómo llegaste al CICSO? ¿Cuál era la parte de la politica en esa adscripción? ¿Qué vínculos tenías con Marin, Murmis, Balvé y otros de los integrantes del Centro?

No fue una adscripción política partidaria sino la intuición de una política general en la que la producción de conocimiento era relevante: un centro que se definia marxista y planteaba la necesidad de la investigación con criterios científicos (frente a cierto irracionalismo sentimental que comenzaban a primar en la facultad), independiente de los partidos políticos, pero no de la política. Creo que no es casual, aunque no fuera consciente, que el núcleo del CICSO (Murmis, Marín, Balvé) viniera del PSAV (luego PVP); de alguna manera me reencontraba con un brazo de la corriente en que me había criado.

La historia de CICSO del que formé parte puede dividirse en cuatro períodos: $1^{\circ}$ ) el CICSO pequeño del $5^{\circ}$ piso D en el $2^{\circ}$ cuerpo de Entre Ríos 131 hasta $1972 ; 2^{\circ}$ ) el CICSO masivo, con cursos que reunían a más de 400 alumnos por cuatrimestre, en el $6^{\circ}$ B en Entre Ríos 131, hasta $1976 ; 3^{\circ}$ ) el CICSO del repliegue que comenzó en la calle Entre Ríos y continuó en Defensa $6655^{\circ}$ C. $4^{\circ}$ ) después de 1983.

Llegué al CICSO en 1968 o 1969 con algunos compañeros de la carrera (Tandeter, Calou, Garavaglia) con los que hicimos el ya mencionado seminario de Laclau-Togneri-Ríos y yo me incorporé al grupo de trabajo de Torre-Moreno-Gutiérrez, que se reunió para discutir bibliografia. Llené la planilla como "miembro adherente" porque para ser miembro pleno había que tener dos trabajos o publicaciones. En ese período el Centro se mantenía con las cuotas de los asociados. Además de los grupos de 
trabajo y seminarios se hacian reuniones donde se discutía sobre distintos temas teóricos y de la situación. Participaban Murmis, Braun, Nun, Nowersztern, Waisman, Laclau, Sigal, Portantiero, D’Alessio, Balvé. También investigadores extranjeros como Stavenhagen y Hobsbawm.

En 1971 estaba trabajando como asistente de Miguel Murmis sobre "La marginalidad en una situación de frontera: el caso del Chaco: los cosecheros de algodón", con las encuestas de marginalidad, una investigación en la que aprendí mucho pero que no terminé. También atendía la puerta y cobraba las cuotas y los cursos. Sobre el final de este período algunos se alejaron para vincularse, de diferentes maneras, a la Juventud Peronista. Lo mismo ocurrió con varios de los que habian sido mis compañeros de la facultad. No fue mi caso, aunque tenía a la JP literalmente en mi cama matrimonial.

En el período del CICSO masivo, fui alumno del curso que dictó Miguel Murmis sobre estructura de clases en el campo argentino. En este período surgieron los Cuadernos de CICSO y publiqué mi primer trabajo de investigación: "Génesis de un semiproletariado rural: la incorporación de los indígenas a la producción algodonera chaqueña".

Hasta $1975 \mathrm{mi}$ relación principal fue con Murmis, que fue quien orientó de hecho la beca de iniciación en la investigación de la UBA que gané en 1972 (la directora formal fue Haydée Gorostegui). Lo mismo cuando gané la beca para hacer el curso 1973-1974 de Formación de Investigadores en Desarrollo Urbano y Regional en el CEUR, que entonces formaba parte del Instituto Di Tella, con la dirección de Guillermo Flichman.

La dirección del CICSO la compartían Murmis, Marín y Balvé, pero cuando en 1975 los dos primeros salieron del país, la dirección operativa quedó a cargo de Beba. A comienzos de 1976 Beba viajó al exterior; en una especie de asamblea se decidió cerrar el CICSO; sólo Inés Izaguirre y yo votamos en contra del cierre. En ese año yo trabajé en el recién fundado Centro de Estudios de Estado y Sociedad (CEDES), invitado como especialista en el tema rural por Marcelo Cavarozzi. A mediados de año, estando yo en las oficinas del CEDES me dicen que tengo un llamado telefónico, atiendo y literalmente me caí sentado en una silla: era Beba que había vuelto y me convocaba a reabrir el CICSO. Se ganó mi eterno respeto a su valentía.

\section{Otra dictadura, otro contexto. ¿Cómo trabajaban?}

A partir de 1977 estuve full time en CICSO. El centro estaba dirigido por Beba y codirigido por Marín desde México. Yo quedé a cargo del programa sobre campo, en el que también estaban Jorge Podestá y Jorge Rozé. 
Cumplíamos riguroso horario de 8 horas. Fue un momento de encierro, pero a la vez de gran riqueza en la formación, en seminarios internos, pero mucho más frecuentemente en las charlas cotidianas, 1o mismo que la discusión de avances de las investigaciones y las cartas que mandaba Marín desde México sobre cuestiones teóricas. Manteníamos la publicación de los Cuadernos de la serie Estudios y de la serie Teoría, en tirajes reducidos y distribuidos muy selectivamente en Argentina y en el exterior. En esta última serie aparecieron los trabajos de Marín, como el "Cuaderno 8", de 1981. En la serie Estudios n 34 publicamos en 1978, con el título "Acerca de la relación poder-saber y la relación saber-poder", una primera versión del libro de Marín Los hechos armados. Un ejercicio posible. Estas publicaciones requerian un trabajo de edición que realizaba Beba y en la que, en la medida de nuestras posibilidades, colaborábamos todos.

En 1979, frente a la exaltación oficial del centenario de la llamada "campaña al desierto", publiqué el Cuaderno serie Estudios no 35 "E1 papel del "estado" en un proceso de creación de condiciones para la constitución de un sistema productivo rural: la "violencia" como potencia económica", casi 10 años después reeditado por el CEAL (también en Estados Unidos y en Dinamarca) como "La violencia como potencia económica: Chaco 1870-1940", que ponía el eje en la coacción como constitutiva de las relaciones productivas capitalistas. Este trabajo circuló bastante no sólo en medios académicos sino también en organizaciones indigenas.

La sorpresa que significó la derrota del peronismo en las elecciones de 1983 llevó a reorganizar las investigaciones: algo había cambiado en el país. Siguiendo el planteo de Gramsci sobre análisis de situación, Jorge Podestá y yo debíamos investigar la relación de fuerzas objetiva, directamente ligada a la estructura, mientras Beba y Beatriz analizaban la relación de fuerzas politicas a través del análisis de solicitadas publicadas en los diarios. Nos llevó casi un año construir los instrumentos que nos permitieran pasar la información de Categoría Ocupacional, Grupo de Ocupación y Rama de Actividad de los Censos Nacionales de Población de 1980 y 1960 a categorías que permitieran medir el grado de desarrollo de las fuerzas productivas y la situación de los Grupos Sociales Fundamentales (clases sociales); y otro para volcar la información. Los resultados se publicaron en los Cuadernos de la serie Estudios $n^{\circ} 46$ ("Análisis de una relación de fuerzas sociales objetiva: caracterización de los grupos sociales fundamentales en la Argentina actual”) y n n 57 ("La población agrícola en la Argentina actual"). Los resultados a los que llegamos en la investigación refutaban el discurso dominante que afirmaba la desaparición o disminución de la clase obrera; por el contrario, al pasar de categorías censales a grupos sociales se hacía observable 
un proceso de proletarización y pauperización y de centralización de la riqueza. Con el Cuaderno $\mathrm{n}^{\circ} 46$ retorné a la actividad docente: fuimos invitados a dictar seminarios y coordinar talleres de metodología de grado y posgrado en las carreras de Sociología y de Historia de universidades nacionales en Río Gallegos, Jujuy, Buenos Aires, Caleta Olivia, Tandil, Mar del Plata, Resistencia, San Juan y Salta. En varios de estos lugares se formaron grupos de investigación que aplicaron los instrumentos presentados en ese trabajo. Además, fuimos invitados a exponer sus resultados y metodologia en diversos grupos políticos e intelectuales.

\section{¿Cuál dirías que fue la ubicación del CICSO dentro del corpus marxista?}

El marxismo del CICSO es el marxismo de Marx. Cuando nos concentramos en la investigación, a partir de 1976, los instrumentos fueron tomados de los textos que nombré más arriba. Uno fundamental es que la lucha entre las clases sociales se da mediante fuerzas sociales que toman la forma de alianza de clases; otro: la centralidad del enfrentamiento.

En todo caso, lo que distinguía a esta orientación era el rechazo a considerar lo económico como directamente determinante. Marín trabajó mucho sobre la noción de "poder" como contracara del "valor". El concepto de Marx de que "La guerra se ha desarrollado antes que la paz", es decir que la "violencia" (ruptura de relaciones sociales) es el operador sobre el que se constituye la sociedad. Probablemente esto se leía con diferentes énfasis, pero coincidiendo en la reflexión de Gramsci sobre la necesidad de encontrar la relación justa entre lo orgánico y lo ocasional, la necesidad y la voluntad.

Desde un comienzo, estaba presente la idea de la incorporación desde una lectura marxista de conocimientos provenientes de otras teorias. Marín impulsó la lectura de Clausewitz, Foucault, Piaget y Prigogine.

¿Cuáles fueron los desafios teóricos y metodológicos que quiso afrontar el CICSO, qué tipo de actividades desarrollaban, cómo se financiaba y funcionaba el centro?

El desafio fue producir conocimiento científico con el instrumental teórico del marxismo y confrontar con otros conocimientos producidos desde otros marcos teóricos, incorporando críticamente sus avances en la medida en que fueran leídos desde nuestra perspectiva teórica. Surge de la necesidad de crear un ámbito de investigación donde se pudiera generar conocimiento científico desde una perspectiva marxista, en estrecha relación con la realidad del movimiento social. Si entendemos que el conocimiento riguroso de la realidad es un arma indispensable en los procesos de confrontación social, nuestra función es construir esas armas. Eso es lo que nos proponemos hoy desde el PIMSA. 
Ese desafio implica dar un fuerte peso a la investigación empírica. No se trata de repetir lo que la teoría dice ni de hacer una declaración de fe marxista para después hacer investigaciones que no se diferencian metodológicamente de las convencionales. Ni de tratar determinados temas pensando que sólo por eso se está haciendo una investigación en una perspectiva socialista científica. Se trata de generar conocimiento riguroso de la realidad con instrumentos teóricos elaborados a partir de la teoría del socialismo científico

Las actividades centrales fueron variando. En el primer periodo (hasta 1972-1973) se hacía investigación y seminarios internos. Se financiaba con los aportes de los miembros y lo recaudado en los grupos de trabajo y seminarios. En el segundo período, bajo la dirección de Murmis y Balvé, se multiplicaron los cursos y se sistematizaron las publicaciones con los Cuadernos de CICSO, que contribuian a financiarlo. En el tercer periodo nos concentramos en investigación. Imposibilitados de hacer cursos y de vender las publicaciones, se buscaron subsidios en el exterior y fue sustancial el de la Agencia Sueca para el Desarrollo.

\section{¿Podrias hablarnos de tu experiencia chaqueña?}

Comenzó por razones estrictamente laborales, pero significó un punto de torsión en mi vida, profesional y personal. En 1969 la antropóloga colombiana Piedad Gómez Villa me ofreció participar en una investigación asentada en el Centro de Investigaciones Sociales, con un equipo interdisciplinario, dirigido por Esther Hermitte, que se hacía por un contrato entre el Consejo Federal de Inversiones y el Instituto Di Tella, por pedido de la provincia del Chaco, sobre el "Estado actual de la población indigena del Chaco y planes para su asimilación a la comunidad nacional". La investigación se desarrolló en 1970 y el resultado fueron 4 tomos mecanografiados que durmieron en la biblioteca del CFI hasta que en 1993 lo publicamos por la Universidad de Misiones. Resultado esperable si se tiene en cuenta que las propuestas del Informe alteraban el mercado de fuerza de trabajo chaqueño.

La primera parte del trabajo de campo (de fin de marzo a junio) fue en la localidad de Misión Nueva Pompeya, en el Impenetrable, cuando no existía la ruta Juana Azurduy, sino que se llegaba desde J.J. Caste1li recorriendo $200 \mathrm{~km}$ de picada, en camioneta o camión siempre que no hubiera llovido; si no, el único medio era a caballo, como hice, de Pompeya a Miraflores, durante dos días del mes de mayo. La segunda parte (julio y agosto) del trabajo de campo fue en el lote 40 de la Colonia Aborigen Chaco, a unos $15 \mathrm{~km}$ de Quitilipi y Machagai.

En las dos localidades me alojé en las escuelas, con mi bolsa de dormir sobre un catre de campaña, los cuadernos con las notas de campo, 
la máquina de escribir, las velas, la linterna y poco más. Caminaba fácilmente una o dos leguas diarias. Tenía una sensación de libertad absoluta mientras andaba por el monte. En Napalpí, de cada casa salian los chamamés de los Hermanos Barrios, que desde entonces tengo asociados a esa sensación de libertad.

Aprendí a conectarme, escuchar y apreciar cómo viven y piensan fracciones sociales con pautas diferentes. Los "pobres" dejaron de ser una abstracción. Sali de la burbuja de la familia y la facultad. Conocí lo que es la pobreza total. Y la realidad chaqueña que se convertiría en mi objeto de investigación durante los siguientes doce años.

¿Cómo fue transitar la experiencia de la dictadura y qué balances sacás de esos años?

La imagen más ajustada oscila entre una "libertad vigilada" y un campo de concentración. Relaciones truncadas por la muerte, el exilio, la prisión o el encierro. Y un repliegue a las relaciones familiares más inmediatas. Una situación de "pueblo ocupado" (Marín, Gramsci). Pero también poder realizar pequeñas acciones de resistencia. Publicar el Cuaderno 34, sobre los hechos armados 1973-1976, o escribir el Cuaderno 35, en directa confrontación con el discurso gubernamental sobre la "conquista del desierto" pero asumiendo la identificación que hacía ese discurso entre "indios" y "subversivos", para mostrar que tanto en 1878 y 1885 como en 1976 el uso de la "violencia" era condición para la imposición de nuevas condiciones productivas. Y, al mismo tiempo, formarnos teóricamente. Creo que sólo tuve una actividad tan intensa en este aspecto cuando formamos el PIMSA.

¿Imaginabas hacer de la investigación tu medio de vida y formar parte de instituciones como el Conicet?

El Conicet y la universidad estaban vedados. Pero sí existía la posibilidad de trabajar en investigación. En 1968-1969 Leandro Gutiérrez me puso en contacto con investigadores visitantes del Instituto Di Tella y trabajé de junta datos. Después fui ayudante en la investigación en el Chaco. En 1972 tuve la beca de la Universidad y fui ayudante de un proyecto de la Universidad Nacional del Sur. En 1973 y 1974 hice el curso del CEUR. En 1975 dirigí una investigación sobre artesanías sanjuaninas (con mucho trabajo de campo) por contrato con el CFI. En 1976 fui investigador visitante en el CEDES y a partir de 1977 y hasta 1992 fui investigador en el CICSO, incorporándome al Conicet en 1985, con asiento en el CICSO, después en IEHS de Tandil y finalmente en el Instituto Ravignani. 